http://jmscr.igmpublication.org/home/

ISSN (e)-2347-176x ISSN (p) 2455-0450

crossref DOI: https://dx.doi.org/10.18535/jmscr/v8i6.76

Journal Of Medical Science And Clinical Research

\title{
Tragal Cartilage v/s Temporalis Fascia: A Comparative Study in Type I Tympanoplasty
}

Authors

\section{Dr Navin Agrawal ${ }^{1}$, Dr Sanjay Kumar Gupta ${ }^{2}$, Dr Saurabh Vijay ${ }^{3}$, Dr Chhavi Agrawal, Dr Mohit Samadhiya ${ }^{4}$, Dr Anand Sharma6, Dr Saket Bansal ${ }^{7}$, Dr Priya Sharma ${ }^{8}$}

${ }^{1}$ Professor \& HOD Of Deptt of ORL, Index Medical College Hospital \& Research Center, Indore

${ }^{2}$ Professor Deptt of ORL, Index Medical College Hospital \& Research Center, Indore

${ }^{3,7,8}$ PG Resident, Deptt of ORL, Index Medical College Hospital \& Research Center, Indore

${ }^{4}$ Associate Professordeptt of ORL, Index Medical College Hospital \& Research Center, Indore

${ }^{5}$ Former PG Resident, Deptt of ORL, Index Medical Hospital \& Research Center, Indore

${ }^{6}$ Senior Resident Deptt of ORL, Index Medical College Hospital \& Research Center, Indore

Corresponding Author

Dr Saurabh Vijay

PG Resident, Deptt of Otorhinolaryngology, Index Medical College Hospital \& Research Center, Indore,

MP, India

\footnotetext{
Abstract

Aim: Comparison of the Temporalis Fascia \& tragalcartilage with perichondrium graft material in Type I tympanoplasty in cases of tubotympanic CSOM.

CSOM can cause significant morbidity in patients due to recurrent discharge, deafness, and various complications. Tympanoplasty is $1^{\text {st }}$ line approach to these problems and prevention of the further complication.

Method: This study involves the patient of tubotympanic type of CSOM presenting in OPD of ORL department in Index medical college, hospital \& research center, Indore from Jan 2017 to June 2019. Patients were divided randomly in two groups. One group was operated using temporalis fascia and another group with tragal cartilage with perichondrium. Pre operative pure tone audiometry was obtained in all the patients. This was compared post operative pure tone audiometry conducted after 12 weeks. Hearing improvement along with other parameters as graft uptake, graft material used and patient's subjective improvement were also noted.

Results: Out of 60 cases 30 were operated using 'temporalis fascia graft' \& rest were with 'tragal cartilage with perichondrium'. On comparison of hearing improvement both the group had no statistical difference in hearing.

Conclusion: Tragalcartilage with perichondrium \& temporalis fascia are both comparable in terms of graft uptake \& hearing improvement.
} 


\section{Introduction}

Chronic otitis media is traditionally defined as chronic inflammation of the mucoperiosteal lining of the middle ear cleft, which is associated with ear discharge, permanent perforation of the tympanic membrane \& hearing impairment. ${ }^{[1]}$ Description of to this disease can be traced in the Greece literature. Hippocrates noted in 460 BC that acute pain in ear with continued high fever is to be dreaded for the patient may become delirious and die. ${ }^{[2]}$ In Pre-antibiotic era complication from CSOM occurred abundantly, accompanied by high mortality. ${ }^{[3]} \mathrm{CSOM}$ is most common ear disease in developing countries ${ }^{[4]}$. It is major infective cause of deafness in India. ${ }^{[5]}$

Tympanoplasty is common surgery for tympanic membrane perforations. The term Tympanoplasty was introduced by the Wullistein in 1953 to describe surgical technique for reconstruction of the middle ear hearing mechanism that has been impaired or destroyed by chronic ear diseases. ${ }^{[6]}$

Fundamentally tympanoplasty is tissue transference procedure. A diverse graft material has been used for closure of the tympanic membrane perforation. Presently most common graft material used for repair of the tympanic membrane is temporalis fascia. Heerman was the first to use temporalis fascia for myringoplasty. ${ }^{[7]}$ In 1963, a cartilage graft for reconstructing a tympanic membrane perforation was introduced by Salen and Jansen. ${ }^{[8]}$ Autologus graft materials for tympanic membrane repair are temporalis fascia, tragal cartilage with perichondrium, chonchal cartilage with perichondrium, fat, dura, tensor fascia lata, vein tissue, periostia, skin. ${ }^{[8-10]}$
Recently a cellular homograft (Allo Derm), a xemograft derived from Bovine pericardium are also used. ${ }^{[11-13]}$

This study has been made to delineate the usefulness of the temporalis fascia and tragal cartilage with perichondrium graft material in terms of graft uptake, dry ear and hearing improvement.

\section{Study Design}

A prospective randomized study has been done with a sample size of 60 patients to compare the outcome of tragal cartilage with perichondrium \& temporalis fascia grafting in patient with CSOM tubotympanic type undergoing type I tympanoplasty.

\section{Material \& Methods}

The present study was conducted over 60 patients of inactive tubotympanic type of chronic suppurative otitis media (CSOM) from our hospital in the Dept of ORL. All the patients were 18- 50 year of age. Detailed history of patients was recorded; examination with emphasis on otologic part was performed.

Examination under was performed in all patients; followed by Pure tone audiometry to assess pre operative hearing loss and $\mathrm{x}$ ray mastoid Schuller's view was performed in all the cases.

Cases were randomly divided into two groups of 30 each. In first group Type I tympanoplasty was performed using Temporalis Fascia Graft material and in second group type I tympanoplasty was performed using tragal cartilage with perichondrium graft material (Fig.1).

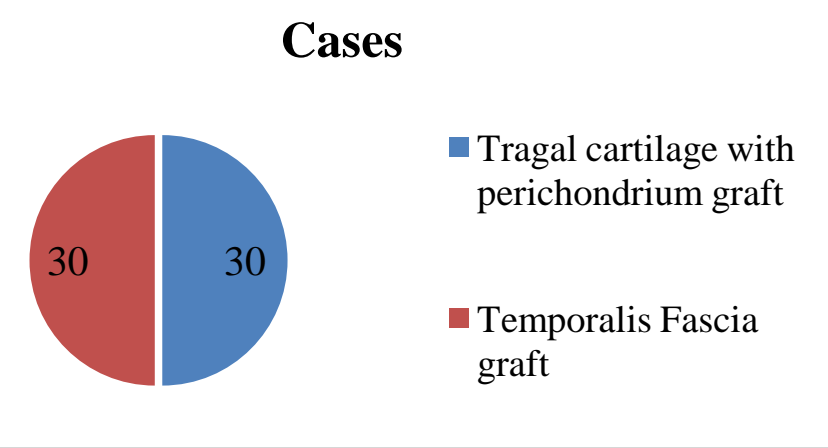

Fig.1 Number of cases in study 


\section{Inclusion Criteria}

Patients with Chronic suppurative otitis media, tubotympanic type were selected for the study. Patient of both genders with age group 18 to 50 years with pure tone air bone gap between 15 to $45 \mathrm{~dB}$ hearing level were included. Operating ear should be dry for at least 6 weeks. Eustachian tube functions were determined by simple OPD procedure I.E. valsalva manoeuvre, air suffalation test.

Non healed traumatic perforations were also included in the study.

\section{Exclusion Criteria}

Patient with atticoantraltype of CSOM were not included in study. Patient who had safe CSOM with sensorineural hearing loss were also excluded. Patient with active discharging ear, cases of ASOM, congenital hearing loss and patient with concurrent diseases i.e. uncontrolled hypertension, Diabetes, severe anaemia were excluded from the study.

Patients with age less than 18 and more than 50 years were excluded.

\section{Operative Procedure}

All patients were operated using post aural approach with Wilde's post aural incision. temporalis fascia graft was harvested from same incision line at just superior to infra temporal line. Tragal cartilage with perichondrium graft was harvested from posterior tragal surface of ipsilateral ear. After graft positioning gel foam soaked in antibiotic was kept in middle ear and external auditory canal. Wound stitches were removed on post operative day 7.Ear canal gel foam was removed on post operative day 21 in both the groups.
Patients were called for follow up on post op 3 weeks, 6weeks and 12 weeks. Graft uptake, audiological improvement, degree of hearing improvement, and complications were studied during follow up visits. Graft take up was assessed by otoscopy and hearing improvement was assessed by postoperative pure tone audiography at 6 weeks and 12 weeks. Post op audiogram of 12 weeks was used for comparison with the pre operative pure tone audiogram.

\section{Observation and Result Graft Uptake}

On post operative examination by otoscopy we found that graft uptake was slightly better for tragal cartilage with perichondrium than temporalis fascia. Graft uptake in temporalis fascia was $83.33 \%$ and in cases operated with tragal cartilage with perichondrium it was $90 \%$ (Table 1). This graft uptake difference was statistically insignificant. This matches with other studies published. Hodzic et al shows the graft success rate was $92.5 \%$ for the fascia group compared with $95.18 \%$ for the tragal perichondrium group. ${ }^{[14]}$ The graft success rate was $92.1 \%$ for the cartilage group compared with $65.0 \%$ for the temporal fascia group in study conducted by Yakub Yagin et al. ${ }^{[15]}$ in contrast in study conducted by Dabholkar et al., graft success rate for the fascia group was $84 \%$, and graft success rate for the tragal perichondrium was $80 \%{ }^{[16]}$

Table 1 Graft uptake

\begin{tabular}{|l|c|}
\hline Graft Type & Uptake of graft \\
\hline Temporalis Fascia & $83.33 \%$ \\
\hline Tragal cartilage with perichondrium & $90 \%$ \\
\hline
\end{tabular}




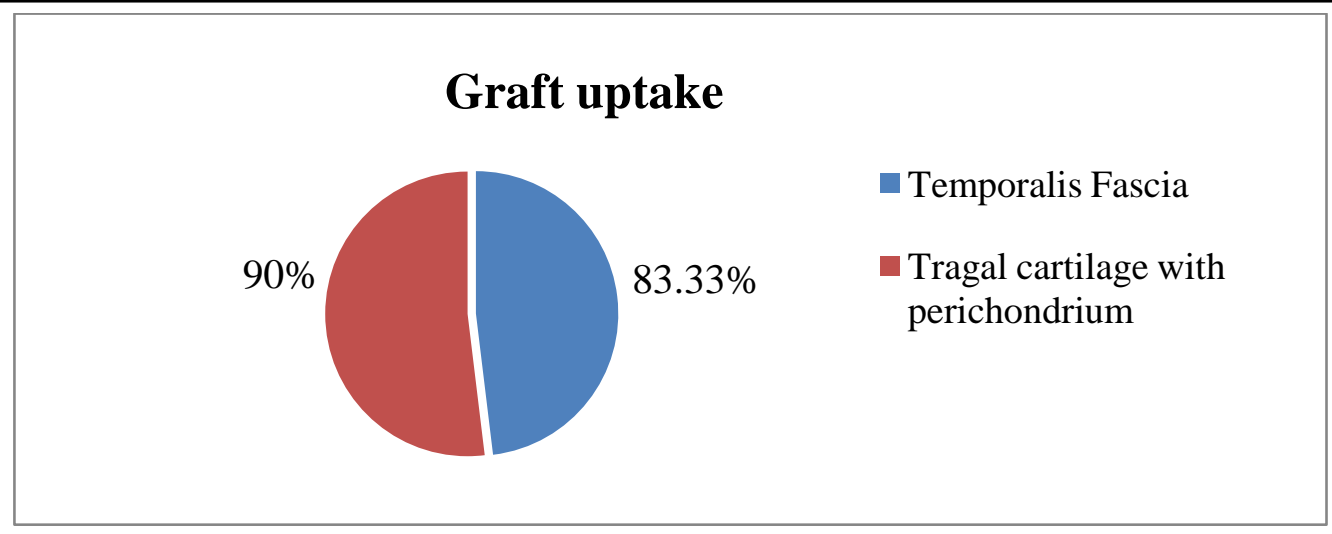

Fig.2 Graft uptake postoperative

\section{Hearing Result}

Tables 2 Mean air bone gap pre \& postoperative and gain in hearing

\begin{tabular}{|l|c|c|c|}
\hline Graft type & Pre operative & Post operative & Gain in hearing \\
\hline Temporalis Fascia & $28.64 \pm 6.75 \mathrm{~dB}$ & $8.66 \pm 2.90 \mathrm{~dB}$ & $16.69 \pm 3.72 \mathrm{~dB}$ \\
\hline Tragal cartilage with perichondrium & $27.75 \pm 4.90 \mathrm{~dB}$ & $7.98 \pm 1.60 \mathrm{~dB}$ & $17.41 \pm 2.66 \mathrm{~dB}$ \\
\hline
\end{tabular}

Measurement of the AB gap closure was taken as a guide to study the degree of hearing improvement. Pure tone audiogram of postoperative 3 month was taken as final outcome of hearing gain. Mean hearing gain in tempralis fascia was $16.69 \pm 3.72 \mathrm{~dB}$ and with tragal cartilage and perichondrium it was $17.41 \pm 2.66 \mathrm{~dB}$ (Table 2). This difference was not significant.

No significant association was found between graft material used for tympanic membrane repair and hearing gain.

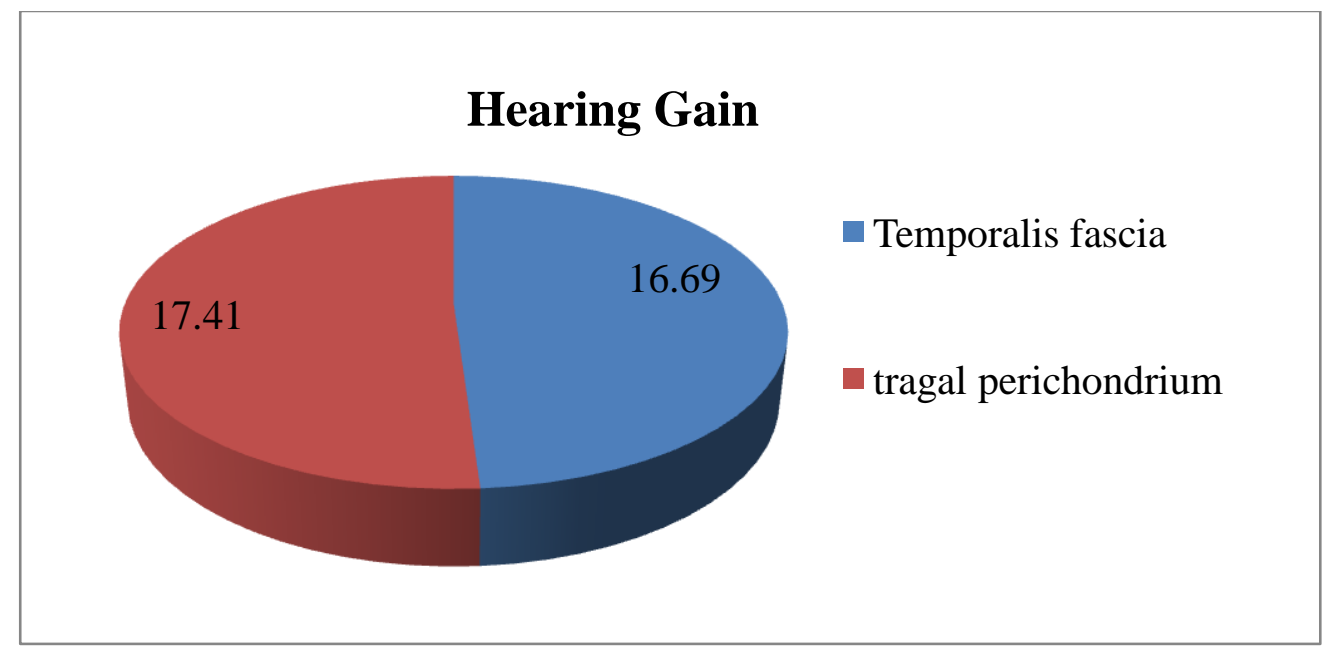

Fig.3 Post operative hearing gain $(\mathrm{dB})$ in both the groups

\section{A-B gap closure in Temporalis Fascia group}

Post operative Air bone gap closure was divided into two subgroups for each group. In the temporalis fascia group A- B gap closure within $10 \mathrm{~dB}$ was found in $80 \%$ and $11-20 \mathrm{~dB}$ was found in $20 \%$ patient in cases of Temporalis fascia graft.
A- B gap closure within $10 \mathrm{~dB}$ was found in 93.3 $\%$ and $11-20 \mathrm{~dB}$ was found in $6.6 \%$ patient in cases of tragal cartilage with perichondriam graft. 


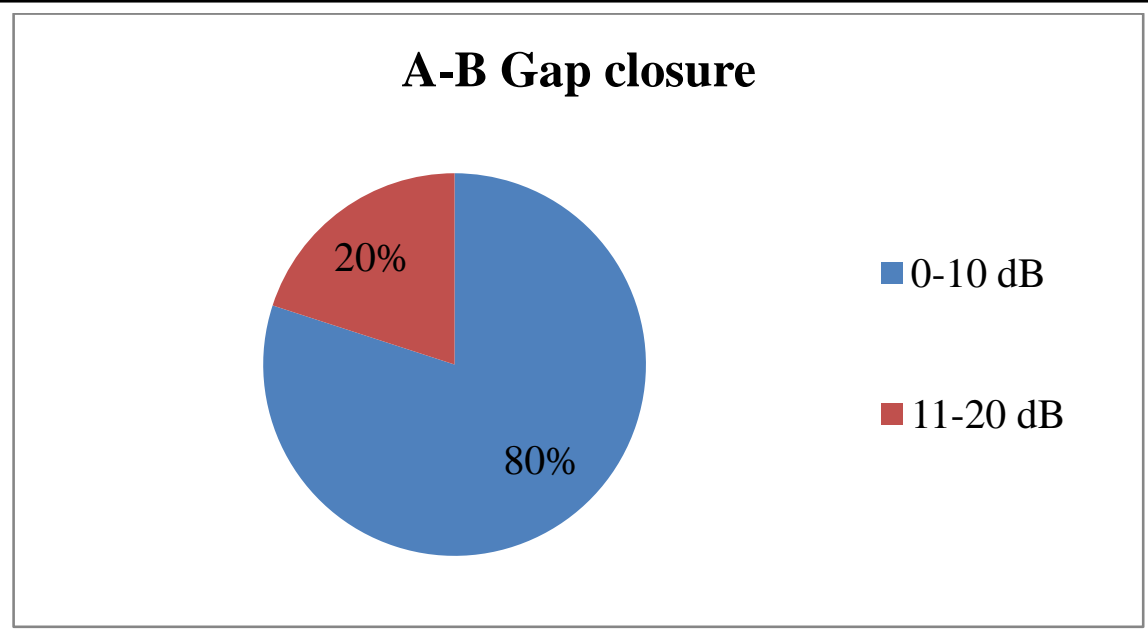

Fig.4 A-B gap Closure in Temporalis fascia group

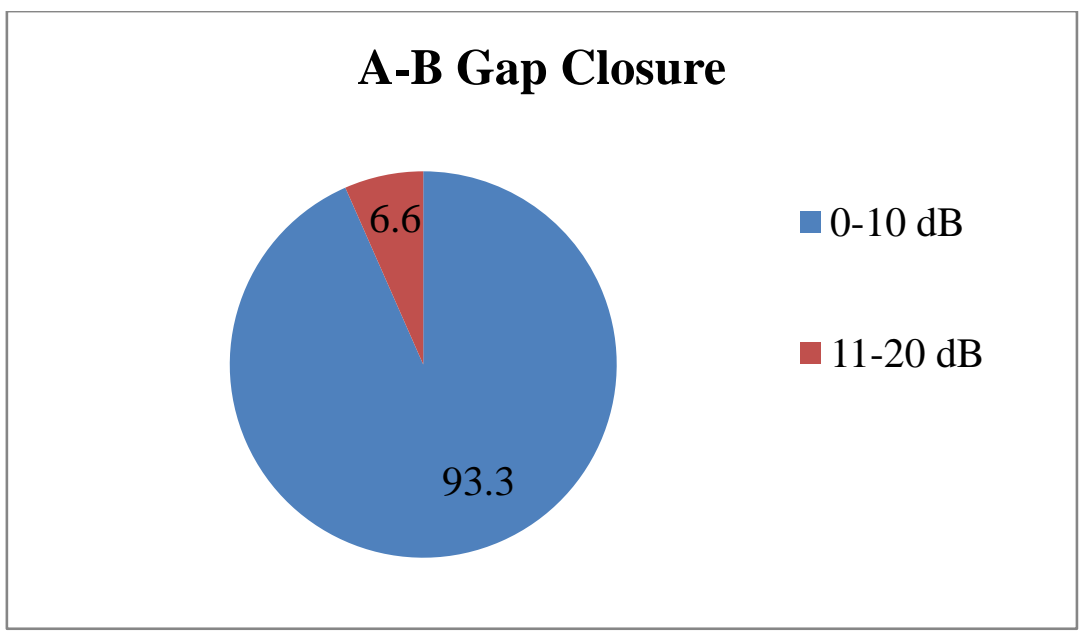

Fig.5 A-B Gap closure in tragal cartilage with perichondrium group

\section{Graft Uptake Failure}

On observation persistent perforation was noted in both the groups. In temporalis fascia group 4 cases had persistent perforation \& in tragal cartilage with perichondrium three such subjects were present. In temporalis fascia group one case had persistent intact retracted drum (Table 3).

Table 3 Graft Uptake Failure

\begin{tabular}{|l|c|c|}
\hline Complication & Temporalis Fascia group & Tragal cartilage with perichondrium \\
\hline Persistent perforation & 4 & 3 \\
\hline Intact retracted drum & 1 & 0 \\
\hline
\end{tabular}

\section{Donor Site Complication}

All complications were found in temporalis fascia group. No major complications were recorded in both the group. During post op Period vomiting nausea, vertigo were noted infrequently.One patient had seroma formation $\&$ one patient came with the hematoma at graft site.

Table 4 Pro and cons of temporalis fascia graft

\begin{tabular}{|l|l|}
\hline Pro & Cons \\
\hline Can be harvested from same post aural incision. & complication at donor site \\
\hline Fascia is similar to Tympanic membrane & Post operative retracted drum \\
\hline $\begin{array}{l}\text { Better air bone closure in comparison to tragal } \\
\text { cartilage with pericondrium }\end{array}$ & More post operative persistent perforation \\
\hline
\end{tabular}


Table 5 Pro and cons of tragal cartilage with perichondrium

\begin{tabular}{|l|l|}
\hline Pro & Cons \\
\hline Easier to obtain the graft & $\begin{array}{l}\text { Can reduce the size of tympanic cavity due to its } \\
\text { thickness }\end{array}$ \\
\hline Better graft uptake than temporalis fascia & $\begin{array}{l}\text { Air bone closure is less than temporalis fascia group } \\
\text { due to thickness \& stiffness of cartilage. }\end{array}$ \\
\hline $\begin{array}{l}\text { Overall hearing improvement is better in tragal } \\
\text { cartilage with pericondrium }\end{array}$ & Cartilage gets slowly reabsorbed with time. \\
\hline Less complication in med in & \\
\hline $\begin{array}{l}\text { More resistant to reperforation (can be used } \\
\text { children with ET dysfunction) }\end{array}$ & \\
\hline
\end{tabular}

\section{Discussion}

CSOM is a major cause of acquired and preventable hearing loss, particularly in the developing world. Myringoplasty restores/ improves patient's hearing and decrease the susceptibility to infection. ${ }^{[17]}$ Temporalis fascia, vein and tragal perichondrium are commonly used graft material. Myringoplasty can be performed using either overlay technique or underlay technique ${ }^{[18,19]}$. The underlay method can be achieved by either trans-canal approach or postaural approach.

Pediatric age group was not included in this study because this age group have high failure rate because of higher chances of eustachian tube dysfunction, middle ear effusion and patient management problems ${ }^{[20-22]}$. Elderly population was excluded from the study because of many associated medical problems like diabetes mellitus, hypertension, presbyacusis and sensory neural hearing loss.

Inactive tubotympanic cases were selected for the study to rule out the focus of infection and resultant graft failure. Patients were selected irrespective of size of perforation and quadrant involved.

All patients were subjected to detailed clinical examination of nose para nasal sinuses and throat to rule out any focus of infection which could affect the result of tympanoplasty. In this study 30 cases were subjected to tympanoplasty with temporalis fascia and 30 patients with tragal cartilage with perichondrium.

\section{Technique of tympanoplasty}

In our study tympanoplasty was performed by post aural route using wilde's incision. Graft harvesting was performed concurrently during surgery. Tempralis fascia graft was harvested from the infratemporal line from the same incision line. It was easy to handle and prepare the graft.

Tragal cartilage with perichondrium graft was harvested from posteriortragal surface and prepared using cartilage slicer. It uses a different incision and comparative difficult to harvest and prepare than temporalis fascia graft. In cases of tragal cartilage with perichondrium graft perichondrium was placed laterally.

Graft placement was done by underlay technique. $\mathrm{Ab}$ gel was kept in Eustachian tube opening and external auditory canal. Post aural incision was sutured in layers. Suture removal was performed on post op day 7 .

The overall female to male ratio in our study was 38: 22 fascia group male to female ratio was 40:60 cartilage group has male to female ratio 33.33: 66.67 the overall male to female ratio was consistent with other studies.

The result of the successful outcome have been evaluated using following criterias

- graft uptake

- hearing improvement

- Donor site complication

- other morbidity

The results were analyzed as per international convention in reporting audiological outcome as performed by American Association of otolaryngology protocol.

the possible predisposition of age towards disease was assessed and it was found that maximum number of subjects that is 20 were from the age group 21 to 30 years followed by 16 in 41 to 50 year and 40 in 10 to 20 year 
The mean age in the temporalis fascia group was $33.5+-12.2$ years, While in tragal cartilage with perichondrium graft group it was $29.7+-10.8$ years the difference was found to be statistically not significant ( $\mathrm{P}$ value $>0.0), 5$ showing that is was compatible between the two grafts groups. similar findings were noted in study of singh et $\mathrm{al}^{(29)}$ in which mean age was 28.9 years and study of dornhoffer ${ }^{(30)}$ in which the mean is was 28 years.

A non significant association was observed between the two graft of graft material and age group revealing that the pattern of distribution of score of various age groups was same in the two Groups for statistical analysis.

\section{Graft Uptake}

The graft uptake in our study was $83.33 \%$ for temporalis fascia and $90 \%$ for tragal cartilage with perichondrium. Graft take rate was slightly better in tragalcartilage with perichondrium than temporalis fascia the marginal difference however is not statistically significant various studies show that graft uptake was in the range of 80 to $90 \%$ for either temporalis fascia for tragal perichondrium. the present study graft uptake rate are reasonable compared to other studies.

Other studies describe graft update rate as follows Abraham $^{(31)}$ noted that graft take up Rate with tragalcartilage with perichondrium by underlay technique was $90.47 \%$. Goodwill ${ }^{(32)}$ reported as a success rate of $100 \%$ in case of primary myringoplasty with tragal perichondrium. Qureshi et $\mathrm{al}^{(33)}$ reported a success rate of $94 \%$ in 32 cases of primary myringoplasty with tragal perichondrium.

Dabholkar $^{(34)}$, Krishna Vora, Abhi Abhik Sikdhar reported that graft uptake rate in comparative study of underlay tympanoplasty with tragal cartilage with perichondrium and temporalis fascia in a series of 50 cases with temporalis fascia and tragal cartilage with perichondrium 84 and $80 \%$ respectively.

Patil et $\mathrm{al}^{(35)}$ reported in their study of 120 cases graft take up of $86.67 \%$ in temporalis fascia, for tragal perichondrium $87.50 \%$ showed successful graft uptake.

Shetty et $\mathrm{a}^{(36)} 1$ in a prospective analysis of 50 patients with csomtubotympanic type reported a 96\% graft take up rate of tragal perichondrium as compared to $92 \%$ in case of temporalis fascia. Hamid et $\mathrm{al}^{(37)}$ included 20 patients of Type 1 tympanoplasty in 10 patients tragal perichondrium was used in 10 patients temporalis fascia was used. They reported graft take up was achieved in $90 \%$ patients where temporalis fascia was used and in $80 \%$ patients where perichondrium was used as graft material.

Majeed $\mathbf{J}$ et $\mathrm{al}^{(38)}$ in their prospective randomized study of 60 patients reported that graft uptake rate of $88 \%$ for temporalis fascia and $83.33 \%$ for tragal perichondrium.

\section{Hearing Results}

The mean preoperative ABG for group I was $28.64+-6.75 \mathrm{~dB}$, for group II was $27.75+-4.90$. The mean post operative air-bone gap for group I was $8.66+-2.90 \mathrm{~dB}$, for group II it was $7.98+-$ 1.60. The mean gain in hearing for group I was 16. $69+-3.72 \mathrm{~dB}$ for group II it was $17.41+-2.6$ dB.

Non significant Association was observed between the graft material and the air bone gap closer revealing that the pattern of distribution of scores of different categories of air- bone closer was same in the two groups statistically. A highly significant difference was observed between preoperative and postoperative air-bone closer, indicating that most of the cases had air bone gap closure and thus gain in hearing. A not significant association was observed between the graft material and the gain in hearing revealing that the pattern of distribution of scores of gain in the hearing was same in the two groups statistically indicating uniform hearing improvement for all the to graft material groups.

In our study mean gain in $\mathrm{ABG}$ was not significantly different between the temporalis fascia and tragal cartilage with perichondrium. The mean gain for temporalis fascia was $16.69 \mathrm{~dB}$ 
with SD of 3.72, and for tragal cartilage with perichondrium was 17.41 DB with SD of 2.6. Our findings are comparable to following studies. Studies conducted by Indorewala ${ }^{(39)}$ mean Gain in ABG was 17 DB for temporalis fascia. Swaminathan et $\mathrm{al}^{(40)}$ reported an average of auditory gain of $10-15 \mathrm{~dB}$ in patient for both temporalis fascia and tragal cartilage with perichondrium. In studies done by Shetty et $\mathrm{al}^{(36)}$ the mean gain in $\mathrm{AB}$ gap in patients using tragal cartilage with perichondrium as graft material was $15.5+-7.27$ decibel as compared to $15+-7.07$ in patients in whom temporalis fascia was used.

In our study with temporalis fascia graft, good caring result, that is, closer rate of a $\mathrm{ABG}$ within 10 days was found in $80 \%$ cases which is comparable to Herman and Tang ${ }^{(41)}(75 \%)$ and the Dabholkar et $\mathrm{al}^{(34)}(76 \%)$, strahan et $\mathrm{al}^{(42)}(82 \%)$, but is less than studies conducted by Gupta and $\operatorname{Mishra}^{(43)}(92 \%)$, and Alan Gibb ${ }^{(44)}(87.5 \%)$.

Average hearing result that is closer between 11 and 20 decibal was found in $20 \%$ cases which is comparable to Dabholkar et $\mathrm{al}^{(34)}(24 \%)$. with tragal cartilage with perichondrium graft closure of $\mathrm{ABG}$ within ten $\mathrm{dB}$ was found in $93.3 \%$ cases which is more than study conducted by Singh et $\mathrm{al}^{(29)}(55.5 \%)$, Dornhoffer ${ }^{(30)}$ (77\%), Dabholkar et $\mathrm{al}^{(34)}(75 \%)$ and is comparable to strahan ${ }^{(42)}(90 \%)$. The closer between 11 and 20 decibel was found to be $6.6 \%$ which is less than the Dabholkar et $\mathrm{al}^{(34)}(25 \%)$.

\section{Donor Site Complication}

One patient had persistent pain while chewing for 3 months in case of temporalis fascia group.One patient in the temporal fascia group noted seroma formation which subsided later. Hematoma noted in one patient in temporalis fascia group which was drained later. All are treated with analgesic and antibiotics.

\section{Failures}

Out of 60 cases three patient of tragal cartilage with perichondrium group had persistent perforation. Four patients of temporalis group have persistent perforation and 1 patient has intact retracted drum.

\section{Conclusion}

- Results of myringoplasty with temporalis fascia were equal to that with tragal cartilage with perichondrium when graft uptake is concerned.

- Tragal cartilage with perichondrium appears to be superior for tympanoplasty regarding hearing improvement \& graft uptake together.

- Temporalis fascia \& tragal cartilage with perichondrium both are excellent graft material for both closure of perforation of tympanic membrane \& hearing improvement without significant difference.

\section{References}

1. Sharma K, Manjari M, Salaria N. Middle ear cleft in chronic otitis media: a clinicohistopathological study. Indian J Otolaryngol Head Neck Surg. 2013;65 (Suppl 3):493-497. https://doi:10.1007/s12070-011-0372-x

2. Borgohain R, Talukdar R, Ranjan $\mathrm{K}$. Otogenic brain abscess: A rising trend of cerebellar abscess an institutional study. Indian J Otol [serial online] 2015 [cited 2020 Jan 12];21:286-9. https://www.indianjotol.org/text.asp?2015/ 21/4/286/165757

3. Heine, B \& Beck, J in Denker, A \&Kahler, O (1927): Handbuch Der Hals- Nasen Ohrenheilkunde. Vol 8, Berlin.

4. Singh, A. \& Kumar, S. Indian J Otolaryngol Head Neck Surg (2010) 62: 121. https://doi.org/10.1007/s12070-0100027-3

5. Varshney S. Deafness in India. Indian J Otol 2016;22:73-6 https://doi.org/10.4103/0971-7749.182281

6. WULLSTEIN H. [Technic and early results of tympanoplasty]. Monatsschr 
Ohrenheilkd Laryngorhinol. 1953 OctDec; 87 (4):308-11.

7. Athanasiadis-Simanis

A (2010)

Tympanoplasty: tympanic membrane repair. In: Gulya AJ, Minor LB, Poe DS (eds) Glasscock-shambaugh surgery of the ear, 6th edn. Peoples Medical Publishing House, Shelton, pp 468-478

8. C. Jansen Cartilage tympanoplasty Laryngoscope, 73 (1963), pp. 1288-1302

9. Saito T, Tanaka T, Toukiri M, et al. Recent outcome of tympanoplasty in the elderly. Otol Neurotol 2001;22920:153-7.

10. E. De Seta, E. Covelli, D. De Seta, P. Mancini, R. Filipo Cartilage tympanoplasty: how to reduce surgery time J Laryngol Otol, 124 (2010), pp. 784785

11. Fayad JN, Baino T, Parisier SC. Preliminary results with the use of Allo Derm in chronic otitis media. Laryngoscope. 2003;113(7):1228-30

12. Fishman AJ, Marrinan MS, Huang TC, Kanowitz SJ (2005) Total tympanic membrane reconstruction: Allo Derm versus temporalis fascia. Otolaryngol Head Neck Surg 132:906-915

13. Gérard JM, Gersdorff M (2006) The Tutopatch graft for transcanal myringoplasty. B-ENT 2(4):177-179

14. Hodzic-Redzic S, Kovac-Bilic L, Branica S. Comparison of tragal perichondrium and temporal fascia grafts in tympanoplasties. Indian J Otol 2018;24:168-71.

15. Yakup Yegin Mustafa Çeliket al. Brazilian jouranla of Otorhinolaryngology vol 82, issue 6, Nov -Dec 2016. P 695-701. https://doi.org/10.1016/j.bjorl.2015.12.009

16. Dabholkar JP, Vora K, Sikdar A. Comparative study of underlay tympanoplasty with temporalis fascia and tragal perichondrium. Indian J Otolaryngol Head Neck Surg 2007;59:116- 9.
17. Packer P, Mac Kendrick A, Solar M (1982) What's best in myringoplasty: underlay or overlay, dura or fascia. J Laryngol Otol 96:25-41

18. Athanasiadis-Simanis A (2010) Tympanoplasty: tympanic membrane repair. In: Gulya AJ, Minor LB, Poe DS (eds) Glasscock-shambaugh surgery of the ear, 6th edn. Peoples Medical Publishing House, Shelton, pp 468-478

19. Browning GG, Merchant SN, Kelly GK, Swan IRC, Canter R, Mckerrow WS (2008) Cronic otitis media. In: Gleeson M, Browning GG, Burton MJ, Clarke R, Hibbert J, Jones NS, Lund VJ, Luxon LM, Watkinson JC (eds) Scott-Brown's otorhinolaryngiology, 7th edn. Hodder Arnold, London, pp 3421-3422

20. Sheehy JL, Anderson RG (1980) Myringoplasty: a review of 472 cases. Ann Otol Rhinol Laryngol 89:331-334

21. Glassock ME III, Jackson G, Nissen AJ, Schwaber MK (1982) Post auricular undersurface tympanic membrane grafting: a follow up report. Laryngoscope 92:718727

22. Caylan R, Ttiz A, Falcioni M, Donato GD, Russo A, Taibah A, Taibah A, Sanna M (1998) Myringoplasty in children: factors influencing surgical outcome. Otolaryngol Head Neck Surg 118:709-713

23. Wullestein H. Method for split-skin covering of perforation of the drum by tympanoplasty operations in cases of chronic otitis. Arch

24. OhrNas- u.Kehlk-Helik 1952; 161:422.

25. Zollner F. Tympanoplasties intented to replace large drum defects combined with defects of ossicles. Panel on myringoplasty.

26. Second workshop on reconstructive Middle Ear Surgery. Arch Otolaryng 1953; 78:301.

27. Zollner F. Abandoned split skin graft because of its low resistance, preferring 
full thickness retro- auricular skin grafts. Proc 5

28. Int Congr Otolaryng 1953; 119Shea JJ. Vein graft closure of ear drums perforations. J. Laryng. 1960; 74: 358.

29. Singh BJ, Sengupta A, Das AK, et al. A comparative study of different graft material used in myringoplasty. Indian $\mathbf{J}$ otolaryngol Head neck Surg.2009;61:1314

30. Dornhoffer JL. Hearing results with cartilage tympanoplasty. Laryngoscope. 1997;107:1094-9.

31. Abraham Aviator. Tragal perichondrium \& cartilage in ear reconstructive surgery. Laryngoscope.11(88):1-23.

32. Goodhill V. Harris I and Brockmann S.J. Tragal Perichondrium and cartilage for myringoplasty. Arch Otolaryn. 1967: 71: 480-491.

33. Qureshi MS, Jones NS. Day care myringoplasty using tragal perichondrium. Clin Otolaryngol Allied sci. 1995:20(1)

34. Dabolkar JP, VoraK, Sikhdar A. Comparative study of underlay tympanoplasty with temporalis fascia and tragal perichondrium. Indian J Otolaryngol Head Neck Surger 2007:59:116-9.

35. Patil K, Baisakhiya N, Deshmukh PT. Evaluation of different graft material in type I tympanoplasty. Indian journal of Otology. 2014:20(3): 106-14.

36. Shetty KA, Velankar HK, Saberwal AA et al. Temporalis Fascia vstragal perichondrium: a comparative study of outcome as graft material in tympanoplasty. Journal of evolution of medical and dental sciences. 2013; 2(52):10172-76.

37. Hameed GS, Prasad BS, Babu PR. A comparative study of temporalis fascia versus tragal perichondrium as a graft in repair of tympanic membrane perforation. Indian Journal of Mednodent and allied sciences , 2015;3 (3): 150-54
38. Majeed J, Ahamed N. Comparative study between tempralis fascia and tragal perichondrium in myringoplasty. Journal of dental and medical sciences. 2016; 15(11):64-72.

39. Indorewala S. Dimentional stability of free fascia graft: clinical application. Laryngoscope 2005;115:278-82.

40. Swaminathan B, Premnivas R, Shanmugam VU et al. A comparative study between tragal perichondrium and temporalis fascia in myringoplasty. International journal of current medical and pharmaceutical research. 20017; 3(7):1993-96.

41. Herman MK. Tang: The perforated ear drum: To repair or not? Hong kong J Online 1989;11:124-5.

42. Straham RW, Aqcquarelli M, Ward PH, Jafek B. Tympanic membrane grafting. Analysis of material and techniques. Ann OtolRhinolLaryngol 1971;80:854-60.

43. Gupta N, Mishra RK. Tympanoplasty in children. Indian J Otolaryngol Head Neck Surge.2002;54:271-3. 